\title{
Mental Illness among Children Working on the Streets Compared with School Children in Duhok
}

\author{
Nezar Ismet Taib, Abdulbaghi Ahmad \\ Department of Neuroscience, Child and Adolescence Psychiatry, Uppsala University, Uppsala, Sweden \\ Email: nezar.ismet@gmail.com, abdulbaghi.ahmad@neuro.uu.se
}

Received 13 July 2015; accepted 27 August 2015; published 1 September 2015

Copyright (C) 2015 by authors and Scientific Research Publishing Inc.

This work is licensed under the Creative Commons Attribution International License (CC BY). http://creativecommons.org/licenses/by/4.0/ (c) (7) Open Access

\begin{abstract}
Child labor is a gradually increasing phenomenon across the world. Children working on the streets are vulnerable to a variety of mental and non-mental illnesses. Due to the scarcity of the research on the health impacts of this phenomenon on these children, this study investigates the risks of mental illnesses and school performance among children working on the streets. A comparative study was conducted from December 16, 2006 to June 10, 2007. The study included 120 boys working on the streets and a comparable sample of non-working boys from primary schools. A modified Family Map was used to collect data on the socio-demographic characteristics. The Mini-International Neuropsychiatric Interview for Children and Adolescence tool was utilized to identify the presence of mental illnesses. The findings show that children working on the streets are five times more likely to be depressed and four times more likely to be anxious than school children. No significant differences are found between the two groups concerning suicide, attention deficit hyperactivity disorder, conduct disorder, tic disorder or school performance. Children working on the streets are more likely to have one or more mental illnesses than the comparable sample of boys attending school regularly. More research is needed to address pathogenesis of mental illnesses as well as resilience of vulnerable children living in a difficult environment.
\end{abstract}

\section{Keywords}

Child Labor, Children Working on the Streets, School Children, Mental Illnesses, Duhok

\section{Introduction}

Child labor on the streets is a growing concern in the entire world. It exists in both developed and developing 
countries. It is believed to be an index related to poverty, families with low literacy level and large extended families (Taib \& Ahmad, 2014).

Globally, it is estimated that around 150 million children are engaged in child labor and approximately 13\% of these children from age 5 to 14 live in developing countries. Sub-Saharan Africa is the region with the highest prevalence of child laborers (25\% of children between the ages of 5 to 14 years old) followed by South Asia with a prevalence of $12 \%$ while Central and Eastern Europe and the Commonwealth of Independent States are the region with the lowest rate of child labor (UNICEF Global Databases, 2014).

It is interesting to highlight the vast variation in the prevalence of child labor between Iraq and the neighboring countries. For instance, in 2011 Iraq had a prevalence of 5.4\% of child labor and in 2010 Iran had a higher level of prevalence of child labor with $12.5 \%$. In 2012 the prevalence was estimated as $7.9 \%$, a figure that was considered to be relatively high. In 2007 Jordan had the lowest rate with a prevalence of $2.8 \%$. In general, the rural parts of all these countries compared to the urban areas present the highest values of prevalence of child labor (UNICEF Global Databases, 2014).

In 1983, the International Labor Organization classified child work into five categories: 1) domestic work such as cleaning, cooking, washing, etc.; 2) non-domestic, non-monetary works such as fuel and water collection, running errands, guarding goods, marketing, etc.; 3) bonded labor, where child workers were kept in bondage because of their families' or their own debt; 4) wage employment, such as part-time, piece-rate work or daily-wage work in domestic, agricultural or industrial areas; and 5) other marginal work on the streets or within informal sectors, which might be irregular or short term such as newspaper rolling, shoe shining or rag picking (Satyarthi, 1989; Valentina, 2000).

All forms of child work violate the child's freedom and human rights and pose negative drawbacks on child development. An important effect is the development of mental health problems. These include functional problems regarding relationships and other social aspects, developmental problems as well as mood and behavior disturbances and other psychiatric symptoms. Some of these symptoms are not fulfilling the criteria of a psychiatric disorder (Imasiku \& Banda, 2015). Development of psychological/psychiatric symptoms are more commonly found in boys coming from separated or reconstituted families, families with low socio-economic status, parents with lower levels of education and families living in non-secure environments.

Experiencing mental health problems varies across countries and cultures. A study aimed to find out mental health problems of 74 Zambian street children between the ages of 7 to 17 found that these children were at risk of having mental health problems and more than one third of them were at risk of experiencing multiple mental morbidities (Imasiku \& Banda, 2015). In a retrospective cohort study on a group of 200 randomly selected working children in the handicraft sector in Morocco, a high prevalence of mental health presentations were found (Laraqui et al., 2000). Another study in Gaza Strip investigated the association between mental health problems and labor related variables among 780 working children (aged 9 - 18 years old) and found a significant association between mental health illnesses and economic determinants. Under-age employment factors varied according to local socio-cultural features. The study also concluded that children who came from large families mainly worked to increase family income, experienced poor friendship relationships, higher anxiety and depression (Thabet et al., 2011).

Despite international concern on the phenomenon of children working on the streets, studies on mental health problems among these children are scarce. Thus, this study aims to identify the differences in the rate of mental illnesses and school performance between children working on the streets and a comparative school sample.

\section{Methods}

\subsection{Subjects}

The subject sample included 120 boys working on the streets who were selected randomly among 200 children from Zewa Center (the only day drop-in center for working and street children in Duhok during the time the study was conducted). Due to the cultural context of the Duhok community only boys can work in the streets and, therefore, only boys were recruited for the study.

The comparison sample was selected from primary school boys $(n=120)$ of the same age group who were chosen randomly after making a list of the names of all primary schools. Four primary schools were selected randomly in the city of Duhok. Every other pupil was selected from the list of the pupils from all four schools until 120 boys were found to be fitting the criteria for the study. 
Inclusion criteria for both samples were boys between the ages of 8 to 17 years old. Children with mental retardation were excluded from the study.

\subsection{Instruments}

1) The Family Map (Genogram) (Penayo, 1990; Ahmad, 1999; Ahmad et al., 2000): A modified family map was used to collect the demographic characteristics of the sample. The items included: age, gender, education, type of work, number of working hours, cause of work, number of years on street, chronic illnesses, disability, surgical operation, economic status, housing, chronic diseases of parent, parent education, parent usual type of work, parent death, age of child when parent died and parent death reason.

2) The Mini International Neuropsychiatric Interview for Children and Adolescents (MINI KID) is a tool that is used to diagnose psychiatric morbidity. This interview is derived from DSM-IV criteria (Sheehan et al., 1998; Sheehan et al., 2010). The researcher interviewed all children to identify all the following diagnoses: depression, suicide, dysthymia, mania, panic, agoraphobia, separation anxiety disorder, social phobia, specific phobias, obsessive compulsive disorder, posttraumatic stress disorder, substance and alcohol abuse, tic disorders, attention deficit hyperactivity disorder (ADHD), conduct disorder, psychotic disorders, anorexia nervosa, bulimia nervosa and adjustment disorders.

\subsection{Ethical Consideration}

An informed assent from the children and written consent from the parents were taken, in which they were clearly informed about the purpose of the study and their right to accept or refuse to participate in the study. The ethical approval had been obtained from the Research Ethics Committee in Duhok Governorate.

\subsection{Statistical Analysis}

SPSS version 17 was used for data analysis. Data were summarized using count (\%). Chi square test or Fisher Exact test (if Chi-square assumptions were violated) were used to test for association or difference. Odds ratio with 95\% confidence interval limits were also calculated to measure the strength of association between the two variables. Level of significance was set at 0.05 .

\section{Results}

Table 1 shows the demographic characteristics of both subject and comparable sample. Their ages range from 9 - 16 years old (mean $=12.3, \mathrm{SD}=1.5)$ and $9-17$ (mean $=12.2$, SD1.4), respectively. More than two-thirds $(\mathrm{n}=$ 120 ) of both groups were from extended families. About $78.3 \%$ of the children working on the streets were forced to work by their parents to get more financial resources for the family.

Children working on the streets showed significantly higher percentage of mental illnesses (40.8\%) compared to the school children $(32.5 \%)(P<0.005)$.

As shown in Table 2, nearly one third of children working on the streets had more than two mental morbidities compared to none of the school children. In addition, $60 \%$ of school children had no mental illnesses compared to $18.3 \%$ of children working on the streets.

The study found that the frequencies of depression and anxiety is significantly higher among children working on the streets (20.8\%, 59.2\%) compared with school children (5.0\%, 25.8\%), respectively $(P<0.001)$.

Table 3 shows that children working on the streets had five times higher rates of being depressed compared to school children (OR = 5) 95\% C-I (1.97 to 12.69). In addition, the first group had approximately four times higher rates of being anxious than the school children (OR = 4.16) 95\% C-I (2.40 to 7.19). Other mental illnesses like suicide, attention deficit hyperactivity disorder (ADHD), conduct disorder, tic disorder showed no statistically significant differences between the two groups $(P=0.065,>0.99,0.120,>0.99$, respectively).

In contrast to the difference in mental illnesses between the two groups, there was no statistically significant difference in school performance between children working on the streets and non-working school children $(P=$ 0.86), as illustrated in Table 4.

\section{Discussion}

Global concern regarding children working on the streets has risen; however, the debate over the effects of this 
phenomenon on the mental health of this vulnerable group has not yet reached the multitude of this problem. This study found that children working on the streets were at higher risk to develop one or more mental illnesses than school children in Duhok City. These results match our previous cross-sectional study conducted in 2004 2005 on street children in Duhok City concerning the rates of anxiety and depression. It found that $98 \%$ of children

Table 1. Subject characteristics.

\begin{tabular}{|c|c|c|}
\hline Variable & Street boys No. (\%) & School boys No. (\%) \\
\hline \multicolumn{3}{|l|}{ Age } \\
\hline Range & 9 - 16 years old & 9 - 17 years \\
\hline Mean & 12.3 years old & 12.2 years \\
\hline \multicolumn{3}{|l|}{ Number of sibling } \\
\hline $1-5$ & $9(7.5)$ & $4(3.3)$ \\
\hline $6-12$ & $96(80)$ & 98 (81.6) \\
\hline$>12$ & $15(12.5)$ & $18(15)$ \\
\hline \multicolumn{3}{|l|}{ Economic state $^{*}$} \\
\hline Good & $0(0)$ & $17(14.1)$ \\
\hline Medium & $18(15)$ & $65(54.1)$ \\
\hline Low & $102(85)$ & 38 (31.6) \\
\hline \multicolumn{3}{|l|}{ Father education } \\
\hline Illiterate & 88 (73.3) & $24(20)$ \\
\hline Primary & $11(9.1)$ & $36(25)$ \\
\hline Secondary & $18(15)$ & 33 (27.5) \\
\hline University & $3(2.5)$ & 27 (22.5) \\
\hline \multicolumn{3}{|l|}{ Mother education } \\
\hline Illiterate & $104(86.6)$ & $67(55.8)$ \\
\hline Primary & $11(9.1)$ & $30(25)$ \\
\hline Secondary & $4(3.3)$ & $15(12.5)$ \\
\hline University & $1(0.8)$ & $8(6.6)$ \\
\hline \multicolumn{3}{|l|}{ Parent death } \\
\hline Father death & $11(9.1)$ & $4(3.3)$ \\
\hline Mother death & $1(0.8)$ & $0(0)$ \\
\hline \multicolumn{3}{|l|}{ Father work } \\
\hline No work or retired & 21 (17.5) & $12(10)$ \\
\hline Worker & $64(53.3)$ & $30(25)$ \\
\hline Peshmergah or solider & $14(11.6)$ & $9(7.5)$ \\
\hline Regular employment & $21(17.5)$ & $65(54.2)$ \\
\hline Higher business class & $0(0)$ & $4(3.3)$ \\
\hline \multicolumn{3}{|l|}{ Mother work } \\
\hline House wife & $116(96.7)$ & 103 (85.8) \\
\hline Regular employment & $4(3.3)$ & $17(14.1)$ \\
\hline \multicolumn{3}{|l|}{ Reasons of working on the streets } \\
\hline Children interest or peer pressure & & $26(21.7)$ \\
\hline Family pressures & & $94(78.3)$ \\
\hline
\end{tabular}

*Estimation of economic state based on 1) father's type of work, 2) other sources of income, 3) house are own or rent, 4) No. of family members and 5) monthly income is below or above the average. Every item mentioned above had given maximum score of 2 and minimum of 1 . (0 - 4) low, (5 - 7) average and (8 - 10) good. 
Table 2. Number of mental illnesses in boys working on street compared to school boys.

\begin{tabular}{ccc}
\hline Number of mental illnesses & Street boys No. (\%) & School boys No. (\%) \\
Nil & $22(18.3)$ & $72(60.0)$ \\
One & $49(40.8)$ & $39(32.5)$ \\
Two & $9(7.5)$ & $9(7.5)$ \\
$>2$ & $40(33.3)$ & 0 \\
Total & 120 & 120 \\
\hline
\end{tabular}

Percentages does not count to 100 due to rounding, Chi square $\left(\mathrm{X}^{2}\right.$ value $=11.52$, d.f. $=2, P$-value $\left.=0.003\right)$

Table 3. Mental illnesses in boys working on street compared to school boys.

\begin{tabular}{ccccc}
\hline Mental illnesses & Street boys No. (\%) & School boys No. (\%) & OR (95\% CI) & $P$-value \\
\hline Total number of studied children & 120 & 120 & & \\
Depression & $25(20.8)$ & $6(5.0)$ & $5(1.97,12.69)$ & $<0.001^{*}$ \\
Suicide & $18(15.0)$ & $9(7.5)$ & $2.17(0.93,5,06)$ & $0.065^{*}$ \\
Bipolar & $1(0.8)$ & 0 & -- & - --** $^{* * *}$ \\
Anxiety disorders & $71(59.2)$ & $31(25.8)$ & $4.16(2.40,7.19)$ & $<0.001$ \\
ADHD & $4(3.3)$ & $5(4.2)$ & $0.79(0.20,3.02)$ & $>0.99^{* *}$ \\
Conduct disorders & $11(9.2)$ & $5(4.2)$ & $2.32(0.78,6.89)$ & 0.120 \\
Tic disorders & $2(1.7)$ & $1(0.8)$ & $2.01(0.18,22.54)$ & $>0.99^{* *}$ \\
\hline
\end{tabular}

${ }^{*}$ Chi square test was used, ${ }^{* *}$ Fisher Exact test was used due violation of Chi-square test assumptions, ${ }^{* * *}$ Calculation not allowed to zero value cells.

Table 4. School performance among boys working on street compared to non-street children indicated by number of years of failure in school.

\begin{tabular}{ccc}
\hline Years of failure in school & Street boys No. (\%) & School boys No. (\%) \\
\hline No delaying & $53(44.1)$ & $56(46.6)$ \\
1 - 2 years & $56(46.6)$ & $55(45.8)$ \\
3 - 4 years & $11(9.1)$ & $9(7.5)$ \\
Total & 120 & 120 \\
\hline
\end{tabular}

Percentages does not count to 100 due to rounding, Chi square $\left(\mathrm{X}^{2}\right.$ value $=0.29$, d.f. $=2, P$-value $\left.=0.86\right)$.

worked on the streets because of the economic needs and pressure on their families. It illustrated higher rates of anxiety and depression among these children (Taib \& Ahmad, 2014).

Similarly, the present study shows that children working on the streets have a significantly higher percentage of anxiety and depression than school children. A high prevalence of anxiety disorders among children working on the streets may be indicative of the cultural context of street children and their families in Kurdistan. Hence, the current study provides more detailed information about the effects of children working on the streets and their mental health status.

However, disruptive disorders (such as ADHD, conduct disorders and tics) showed no significant differences between the two groups. This can be explained by the role of genetics in addition to the environment in the process of development of disruptive illnesses. There is consistency in the literature that genetic factors play an important role in the development of ADHD and in the continuity of its symptoms later in a person's life. This susceptibility is increased by environmental risk factors (Thapter, Langley, Asherson, \& Gill, 2006). Exposure to environmental risk factors in the pre-, peri-, and postnatal period appears to play some roles in the pathogenesis of ADHD (Curatolo, D’Agati, \& Moavero, 2010).

School performance was not significantly different between the two groups and this might be due to the supportive educational program delivered in Zewa Center where all these children had received schooling. Educational program such as the Zewa Center appeared to have positive impacts on children's school performance.

The study is not without limitations. Years of failure was used as a parameter to indicate school performance 
and it would be much better if final exam scores were used as an indicator of school performance. Inaccurate administration of the questionnaire was another possible shortcoming; however, this was overcome by the researchers as they, who were trained child psychiatrists, interviewed the children using tools derived from international standards based on DSM4. This can be considered as strength points of the study.

In conclusion, the present study shows that children working on the streets reveal higher rates of environmental mental illnesses compared with school children in the same gender and age group in Duhok City. Whether the mental illness is a cause of working on the streets and thus increases the risk of development of mental illness has to be addressed in further research. Additionally, there are other questions that need to be answered such as the mechanisms of psychopathology of children living in difficult circumstances, environmental factors versus biological and genetic factors, and the resilience of children living in vulnerable environment.

\section{Acknowledgements}

The authors are grateful to all children for participating in this study. Our thanks also go to Dr Frank Lindblad and to Professor Abdulmanaf Al-Jadiry for their supervision and contribution in this study.

This study was funded by the World Health Organization.

\section{References}

Ahmad, A. (1999). Childhood Trauma and Posttraumatic Stress Disorder: A Developmental and Cross-Cultural Approach (Comprehensive Summaries of Uppsala Dissertations). Stockholm: Uppsala Universitet.

Ahmad, A., Sofi, M. A., Sundelin-Wahlsten, V., \& von Knorring, A. L. (2000). Posttraumatic Stress Disorder in Children after the Military Operation “Anfal” in Iraqi Kurdistan. European Child \& Adolescent Psychiatry, 9, 235-243. http://dx.doi.org/10.1007/s007870070026

Curatolo, P., D’Agati, E., \& Moavero, R. (2010). The Neurobiological Basis of ADHD. Italian Journal of Pediatrics, 36, 79. http://dx.doi.org/10.1186/1824-7288-36-79

Imasiku, M. L., \& Banda, S. (2015). Mental Health Problems of Street Children in Residential Care in Zambia: Special Focus on Prediction of Psychiatric Conditions in Street Children. Journal of Clinical Medicine and Research, 7, 1-6.

Laraqui, C. H., Caubet, A., Laraqui, O., Belamallem, I., Harourate, K., Curtes, J. P., \& Veger, C. (2000). Child Labour in the Artisan Sector of Morocco: Determinants and Health Effects. Sante Publique, 12, 31-43. (Article in French)

Penayo, U. (1990). On Mental Disorders in Nicaragua: An Epidemiological Approach. Umeå: Umea University.

Satyarthi, K. (1989). Child Bonded Labor in South Asia: An Overview. Into that Heaven of Freedom? Report on South Asia Seminar on Child Servitude, 84-87.

Sheehan D. V., Lecrubier, Y., Sheehan, K. H., Amorim, P., Janavs, J., Weiller, E., Hergueta, T. et al. (1998). The MiniInternational Neuropsychiatric Interview (M.I.N.I.): The Development and Validation of a Structrured Diagnostic Psychiatric Interview for DSM-IV and ICD-10. The Journal of the Clinical Psychiatry, 59, 22-23, quiz 34-57.

Sheehan, D. V., Sheehan, K. H., Shytle, R. D., Janavs, J., Bannon, Y., Rogers, J. E., Milo, K. M. et al. (2010). Reliability and Validity of the Mini International Neuropsychiatric Interview for Children and Adolescents (MINI-KID). The Journal of Clinical Psychiatry, 71, 313-326.

Taib, N. I., \& Ahmad, A. (2014). Psychiatric Morbidity Among Street Children in Duhok. Clinical Medicine Insights: Pediatrics, 8, 11-16. http://dx.doi.org/10.4137/CMPed.S13505

Thabet, A. A., Matar, S., Carpintero, A., Bankart, J. \& Vostanis, P. (2011). Mental Health Problems among Labour Children in the Gaza Strip. Child: Care, Health \& Development, 37, 89-95. http://dx.doi.org/10.1111/j.1365-2214.2010.01122.x

Thapter, A., Langley, K., Asherson, P., \& Gill, M. (2006). Gene-Environment Interplay in Attention-Deficit Hyperactivity Disorder and the Importance of a Developmental Perspective. The British Journal of Psychiatry, 190, 1-3.

UNICEF Global Databases (2014). UNICEF Data: Monitoring the Situation of Children and Women. http://data.unicef.org/child-protection/child-labour

Valentina, F. (2000). Challenges in Combatting Child Labor from an Occupational Health Perspective. Asian Pacific Newsletter, 2, 28-31. 